\title{
Hippocrates in Quebec: The films of Bernard Émond
}

Previously published at www.cmaj.ca

$\mathrm{R}$ epresentations of the physician in popular cinema typically range from doctor as superhero to conscientious caregiver to, occasionally, cruel or indifferent monster. Regardless of the nature of these representations, however, the physician has been invariably depicted as someone who has access to profound and mysterious knowledge.

In the Canadian cinema specifically, there are a number of fascinating physicians, both good and bad: the pedophiliac predator David Sutton in Anne Wheeler's Loyalties (1986); the deranged twin gynecologists in David Cronenberg's Dead Ringers (1989); the sweetly altruistic, if socially naive, community saviour Dr. Christopher Lewis in Seducing Doctor Lewis (2003). While these films probe the social, economic and even political implications of medical practice, their dramas generally do not explore the complexities and, yes, mysteries of the underlying philosophy of why one actually becomes a physician in the first place.

Perhaps such philosophy cannot be filmed; on the other hand, perhaps it can. One acclaimed Canadian filmmaker is attempting to do just that.

Imagine that on your travels along the Saint Lawrence River or to the Abitibi region of Quebec you come face-to-face with Hippocrates. Not literally, of course, but you will encounter, in the thoughtful films of writer-director Bernard Émond an investigation into how the role of the physician requires a renewed recognition of the philosophy of Hippocrates and a careful consideration of the consequences of embracing that philosophy in one's medical practice.

Émond's two films La Veuvaine (The Novena) (2005) and La Donation (The Legacy) (2009) are the first and third parts of a trilogy of films based on

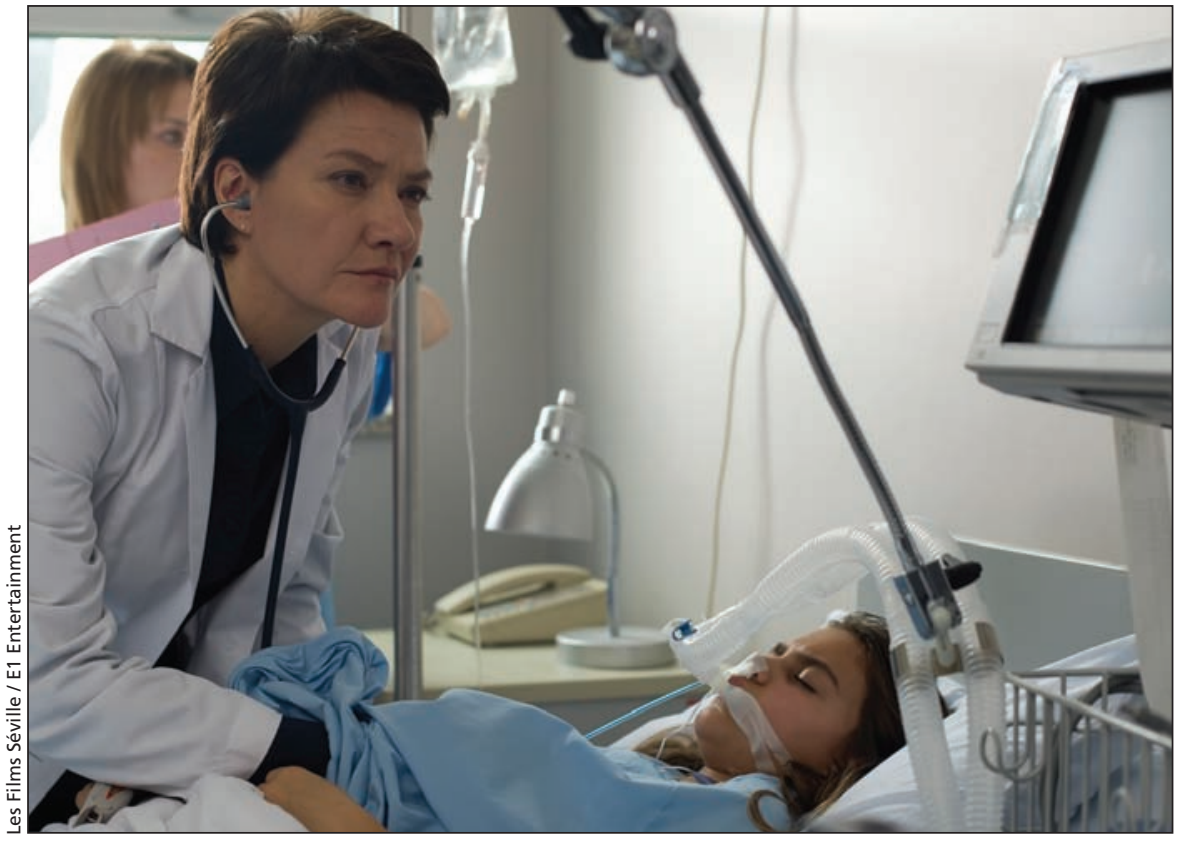

In La Donation, Dr. Jeanne Dion, a Montréal, Quebec, emergency department physician, continues to search for a larger meaning within her chosen profession.

the Christian ideals of faith, hope and charity (both available in English subtitled DVD versions). They are exquisitely rendered, quiet dramas revolving around the life of Dr. Jeanne Dion, a Montréal, Quebec, emergency department doctor faced with crises of conscience about her profession and its larger meaning in the world.

The Novena is the story of Dion's flight from the chaos of Montréal, where she witnesses a terrible incident involving one of her patients. Driving east, she ends up in a small town where she encounters François, a young man on a religious pilgrimage to save his dying grandmother. Dion's existential and professional crises are recast in the context of her friendship with François and her helping him, as a physician, to accept the inevitable fate of his beloved grandmother.

The healing is mutual for these characters and, as always in Émond's films, it is a process that is largely unspoken. Dion attempts to balance compassion and dispassion in her professional self while confronting, on a more personal level, the deeper and perhaps more spiritual mysteries of life and death, suffering and healing.

A more thorough dramatization of these questions occurs in The Legacy. Its philosophical drama is set in Normètal, a small town in the Abitibi region of Quebec. It begins when the elderly town doctor, Yves Rainville, becomes ill and advertises for a physician to replace him temporarily. When Dion drives to Normétal to fill the position, she is impressed by Rainville's philosophy of medicine in his modest, but longstanding practice. She tells him of how she feels "outside the suffering" of her patients, and seeks a way back toward the more holistic approach advocated by Hippocrates and seemingly embodied by Rainville. As the 
film progresses, she becomes involved with his patients and the complexities of their medical conditions and their lives. Near the film's conclusion, she has to decide whether she is prepared to take on Rainville's practice permanently.

Dion's twin journeys don't offer simplistic resolutions to her professional quandaries, nor do they romanticize rural medical practices over urban

ones. What these understated, meditative films do register is a sense of medicine as a vocation with spiritual connotations, as if the mystery of the human soul must be seen to be part of how medicine is practised in a world of advanced scientific technologies and treatments. Rainville states matter-offactly that he is "here to serve." His humility appears genuine, tough-

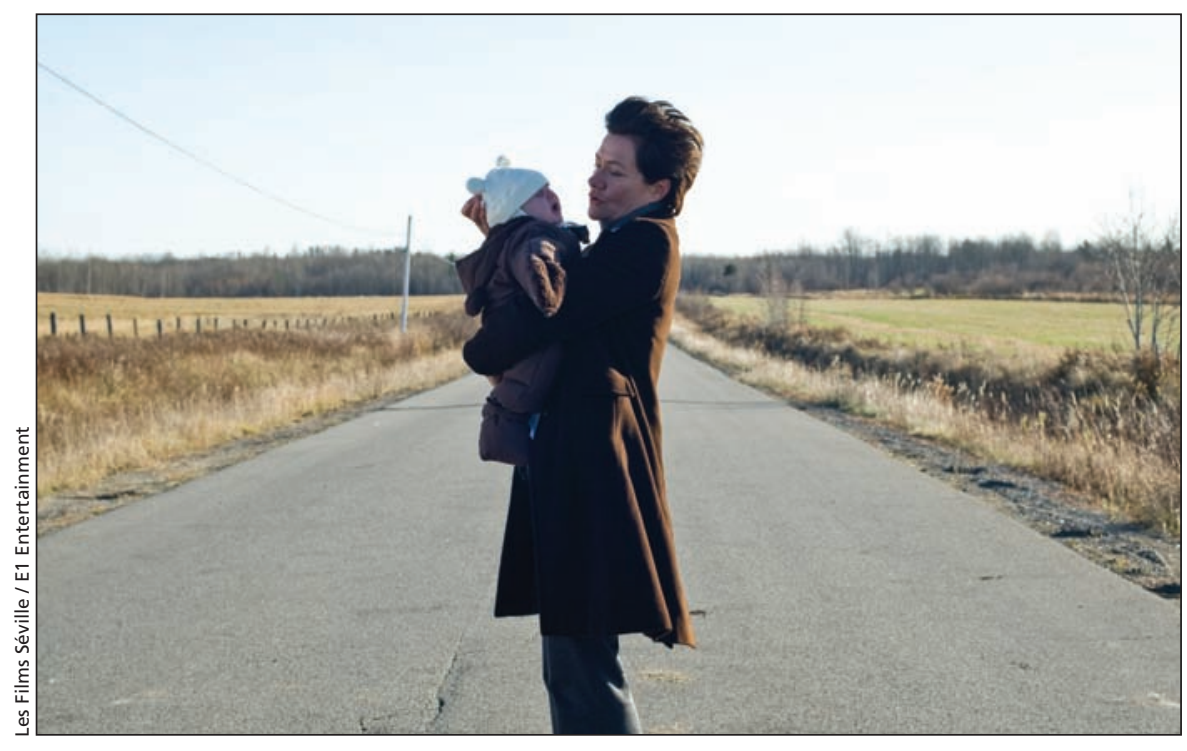

Dion takes on a small-town practice in the Abitibi region of Quebec and discovers the way back toward a more compassionate approach to medicine. minded and practical for a physician, and it inspires Dion with the quiet force of its example.

Émond's depiction of Dion's crises, her sense of her limitations as a doctor and her shaken but not destroyed commitment to compassion, is as sobering as it is hopeful.

The films intelligently raise important moral, ethical and philosophical questions about the role of the physician in society. These are the same questions raised by Hippocrates, questions that are both essential and, in a paradoxical sense, unanswerable. What is essential is not their being answered but rather the raising and reframing of these questions, as medical science evolves, in contemporary social contexts and changing medical practices. Films like The Novena and The Legacy contribute to that process in both useful and aesthetically impressive ways.

\section{Tom McSorley}

Executive director

Canadian Film Institute

Ottawa, Ont.

Tom McSorley is a sessional lecturer in the Department of Film Studies at Carleton University, Ottawa, Ont. and film critic for CBC Radio One's, Ottawa Morning.

\section{Wanted: Historical artifacts for new public health school}

$\mathrm{W}$

hy decorate walls with accent colours and bad art when you can use the space to educate the public and students? That's the thinking behind the proposed public health museum (both actual and virtual) at the School of Population and Public Health's newly renovated building at the University of British Columbia, Vancouver, BC.

"We already have some remarkable - objects," says Dr. Erica Frank, a professor at the school and the museum's organizer. These include an iron lung, quarantine signs, an old British Columbia Centre for Disease Control public health laboratory, immunization paraphernalia, the Nobel Peace prize certifi- cate awarded to the International Physicians for Prevention of Nuclear War and art about mental illness. The building is slated to open in summer 2010.

Frank is looking to borrow other public health related artifacts (erica.frank @ubc.ca).

Many of the objects will be accompanied by a narrative and photograph of a person who benefited from the object. For example, a woman whose father was in an iron lung for two years will write about how that experience allowed her to exist.

Another twist is that this summer's intern will be Frank's 12-year-old son, Ridge Frank-White, who will be making a photographic record of all the objects to put on a website. "I know, it's an age-inappropriate activity," quips Frank. "But some parents like to play soccer or hockey with their kids; I like to work with mine." Frank-White has attended all the planning meetings and helped to situate the exhibit spaces.

"It's going to be great," says Frank. "It sure beats hanging trite motivational posters on the wall."

\section{Barbara Sibbald BJ}

Deputy editor, analysis and humanities CMAJ

Erica Frank is a member of the CMAJ editorial board. 